\section{The North Sea bubble}

Fossil fuels are likely to provide most of our power for the foreseeable future, but that does not mean that all the $\mathrm{CO}_{2}$ produced has to go into the atmosphere. Norwegian company Statoil is pioneering attempts to store the gas elsewhere - deep below the seafloor. As Statoil's underground gas bubble grows, so do hopes that the technique could deal with more of the troublesome greenhouse gas.

The $\mathrm{CO}_{2}$ is an impurity in the natural gas that Statoil extracts from the North Sea Sleipner gas fields. It is normally separated and released into the atmosphere, but since 1996 the company has been pumping the gas into a layer of sandstone around 1 kilometre below the seabed. Known as the Utsira formation, the layer traps the gas in a gigantic bubble which now contains some four million tonnes of $\mathrm{CO}_{2}$.

Once separated from the natural gas, the $\mathrm{CO}_{2}$ is compressed before being pumped into the reservoir, where the high pressure keeps it in a dense 'supercritical' state - a hybrid of gas and liquid phases. This limits the diffusion of $\mathrm{CO}_{2}$ through the sandstone. A layer of shale, which is impermeable to the $\mathrm{CO}_{2}$, sits on top of the sandstone, effectively sealing the reservoir.

Andy Chadwick of the British Geological Survey is part of a team of European scientists

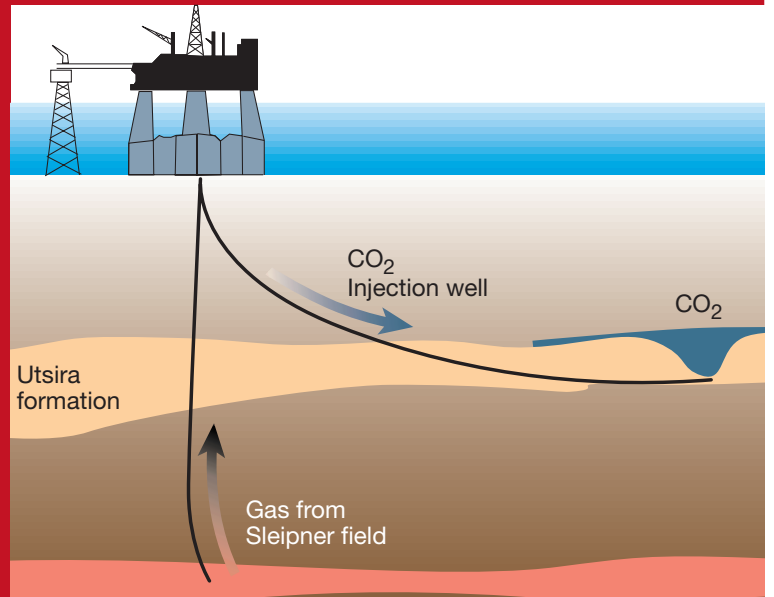

responsible for monitoring the project. The team's 1999 seismic survey showed that the $\mathrm{CO}_{2}$ is trapped within the reservoir and will probably stay there indefinitely. Chadwick is impressed with the project so far, but warns that the $\mathrm{CO}_{2}$ may start to compress, rather than dissipate through the reservoir, making it progressively harder and more expensive to inject more gas.

But the Sleipner project's success does not necessarily imply that similar schemes could be applied to $\mathrm{CO}_{2}$ from power plants. At Sleipner, the $\mathrm{CO}_{2}$ would have been extracted from natural gas anyway, regardless of any storage scheme. Separating the $\mathrm{CO}_{2}$ produced by power plants would require new investment, increasing the price of electricity. Additional infrastructure would also be needed to transport the gas to the reservoir. But the potential for storage is huge: just $1 \%$ of the reservoir Statoil is using, says Chadwick, could hold three years' emissions from all of Europe's power stations.

For Statoil, the Sleipner project has actually saved the company money. Norway taxes offshore carbon emissions to the tune of $\$ 38$ per tonne. Before January 2000 , the price was $\$ 50$ per tonne. By storing one million tonnes of $\mathrm{CO}_{2}$ undersea every year and avoiding this tax Statoil recouped its $\$ 80$ million investment within two years. The company plans to run the project for 20 years, storing around one million tonnes of $\mathrm{CO}_{2}$ every year - equivalent to $3 \%$ of Norway's current total annual emissions.

David Adam
The latest IPCC report, issued earlier this year, stated that global temperatures were rising faster than previously thought and that there was strong evidence that greenhouse gases were the cause (see Nature 409, 445; 2001). But Frank Sprow, vice-president of safety, health and the environment at ExxonMobil, says that most of the evidence linking greenhouse gases to global warming comes from climate models, rather than empirical data. "I think the layman and even some scientists don't understand that the question of attribution has to rely on models," Sprow says. He also claims that the report's executive summary played down substantial uncertainties within the document.

Joyce Penner, an atmospheric modeller at the University of Michigan in Ann Arbor, denies this. "The summary for policymakers does tell the story," she says. Penner was a lead author on the IPCC report chapter dealing with atmospheric aerosols, one of the largest sources of uncertainty in understanding climate change. "If you choose to ignore some of the things said there then you will get a skewed view," she says.

\section{Pouring oil on troubled waters}

Sprow does not deny that the build up of greenhouse gases poses long-term risks, but he argues that the Kyoto Protocol is not the way to deal with them. Instead, ExxonMobil advocates a three-tiered voluntary response to climate change. The initial focus is on energy conservation, followed by advances in technologies that reduce $\mathrm{CO}_{2}$ emissions, and finally breakthroughs in areas such as carbon sequestration, which aims to lock emitted $\mathrm{CO}_{2}$ away so that it cannot enhance the greenhouse effect.

Sawyer says such a strategy is unacceptable: "All it means is delay and taking actions which are of no conceivable cost to them at some undefined point in the future."
Steve Cochran, a spokesman for Environmental Defense, agrees. "Exxon has been extraordinarily difficult," he says. "It has funded efforts such as the GCC, which has worked very hard to undermine legitimate scientific understanding."

Greenpeace and other environmental groups have reacted by launching a European boycott of ExxonMobil and other American oil companies such as Texaco and Chevron. Sawyer says the goal is to provide encouragement for companies that do support Kyoto. In the long term, they hope to convince the United States to reconsider its decision.

If the boycott works, it may force ExxonMobil to factor consumer demand for environmentally friendly products into its long-term plans. Balancing environmental demands from the public and governments with the need to maintain profits will be a key challenge in the future for the oil industry.

Returning to Stanford earlier this year to give an update on BP's work on climate change, Browne described how the job of providing energy can feel like a trade-off between economic growth and a healthy environment. "I believe there is a huge commercial prize for those who can offer better choices which transcend the trade-off," he said.

The divergent climate-change policies of the oil giants are, in effect, speculations that reflect different views about that prize. Shell and $\mathrm{BP}$ are trying to position themselves as the main providers of the energy sources that may succeed fossil fuels. "They want to be there first," observes Claussen. ExxonMobil, on the other hand, appears to have decided that it can make more money by continuing under the present system for as long as possible - and catching up on alternative energy technologies at a later date.

Gordon Edge, an analyst with FT Energy in London, says ExxonMobil's decision will help profits in the short term, but will cause problems as renewables become more important. "Adjusting to renewables involves a major culture change. Exxon could take a decade to catch up," says Edge.

The long-term payoffs of all the companies'strategies are difficult to judge. But what is clear is that the outcome will affect us all: in gambling on their business futures, the oil giants are staking the Earth's climate.

Mark Schrope is a freelance writer in Melbourne, Florida.

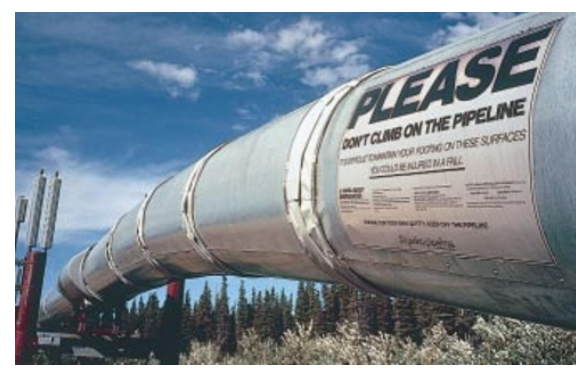

Pipe dreams: US companies seem reluctant to invest in renewable sources to replace fossil fuels. 